\title{
Correlation between radiological and biological features and clinical outcomes in early prostate cancer: an exploratory subgroup analysis
}

\author{
Giulia CORRAO ${ }^{1,2, *}$, Giulia MARVASO ${ }^{1,2, *}$, Mattia ZAFFARONI ${ }^{1, *}$, Stefania VOLPE ${ }^{1,2}$, Matteo AUGUGLIARO ${ }^{1}$, Cristiana Iuliana FODOR ${ }^{1}$, Dario \\ ZERINI $^{1}$, Andrea VINGIANI ${ }^{2,3}$, Francesco Alessandro MISTRETTA ${ }^{4}$, Stefano LUZZAGO ${ }^{4}$, Sarah ALESSI ${ }^{5}$, Paola PRICOLO ${ }^{5}$, Gennaro MUSI $^{2,4}$, \\ Ottavio DE COBELLI ${ }^{2,4}$, Giuseppe RENNE ${ }^{3}$, Marco MANZONI ${ }^{3}$, Giuseppe PETRALIA ${ }^{2,6}$, Roberto ORECCHIA ${ }^{7}$, Barbara Alicja JERECZEK-FOSSA ${ }^{1,2}$
}

\begin{abstract}
${ }^{1}$ Department of Radiation Oncology, European Institute of Oncology IRCCS, Milan, Italy; ${ }^{2}$ Department of Oncology and Hemato-Oncology, University of Milan, Milan, Italy; ${ }^{3}$ Department of Pathology, European Institute of Oncology IRCCS, Milan, Italy; ${ }^{4}$ Division of Urology, European Institute of Oncology IRCCS, Milan, Italy; ${ }^{5}$ Department of Radiology, European Institute of Oncology IRCCS, Milan, Italy; ${ }^{6}$ Precision Imaging and Research Unit, Department of Medical Imaging and Radiation Sciences, European Institute of Oncology IRCCS, Milan, Italy; ${ }^{7}$ Scientific Direction, European Institute of Oncology IRCCS, Milan, Italy
\end{abstract}

${ }^{*}$ Correspondence: mattia.zaffaroni@ieo.it

${ }^{*}$ Contributed equally to this work.

Received June 22, 2021 / Accepted August 23, 20219

\begin{abstract}
PTEN deletion and Ki-67 expression are two of the most promising biomarkers in prostate cancer (PCa). In the same manner, multiparametric magnetic resonance imaging (mp-MRI) guided core biopsy is a powerful tool for PCa detection and staging. The aim of the study is to assess whether a correlation can be identified between the pathological stage defined by an mp-MRI-guided core biopsy and Ki-67 expression and PTEN deletion. Such correlation might be useful for staging and treatment personalization in PCa. This investigation was conducted in the context of phase II clinical study "Short-term radiotherapy for early prostate cancer with a concomitant boost to the dominant lesion" (AIRC IG-13218), ClinicalTrials. gov identifier: NCT01913717. Nineteen patients underwent a further in-bore MRI-targeted core biopsy (MRI-TBx) on the dominant intraprostatic lesion (DIL); on this basis, an additional Gleason Score (GS) was determined. PTEN loss and Ki-67 expression on these samples were analyzed and correlated with both risk categories modifications and oncological outcomes (overall survival, biochemical and clinical relapse). GS was upgraded in 5 cases, with 4 patients re-classified as intermediaterisk and 1 patient as high-risk. The latter experienced a clinical local relapse. No correlations between up/down-staging, PTEN deletion, and Ki-67 expression were observed in this cohort. Further investigations are needed towards the identification of a pattern in the tumor aggressiveness-response in PCa treated with ultra-hypofractionated radiotherapy. Moreover, a possible relationship between biomarker analysis and imaging textural features could be explored.
\end{abstract}

Key words: PTEN, Ki-67, biomarkers, early prostate cancer, $m p-M R I$

Prostate cancer $(\mathrm{PCa})$ is the most frequently diagnosed cancer in North American and European men [1]. Despite the use of advanced and combined approaches, a substantial percentage of patients do not respond to treatments [2]. The challenge for the future is to identify sub-classes of patients for which standard treatments could fail, in order to improve personalized strategies. Blood tests, histopathology markers, and imaging studies are contributing to realizing this transition [3], and possibly will be gradually incorporated into clinical practice.

Nowadays, multiparametric magnetic resonance imaging (mp-MRI) is the most accurate imaging technique for organconfined PCa, with $80 \%$ sensitivity for tumor detection [4] (86\% with tumors greater than $0.5 \mathrm{~cm}^{3}$ ) [5]. Several MRI parameters can be considered for the radiological characterization of the disease, namely: Prostate Imaging Reporting and Data System (PI-RADS), Extra-Prostatic Extension score (EPE), Apparent Diffusion Coefficient (ADC), number and position of Dominant Intraprostatic Lesion (DIL), prostate volume. The use of mp-MRI can be extended to MRI-guided target core biopsy on the highest PI-RADS DIL to determine the correct staging through the higher Gleason Score (GS). This technique allows determining DIL histopathological characteristics with high precision, in contrast with the more commonly used transrectal ultrasound core biopsy (TRUS). Currently, the assessment of risk classes, according to National Comprehensive Cancer Network (NCCN) guidelines [6], is based on Prostate Specific Antigen (PSA) value, 
International Society of Urological Pathology (ISUP) score grade [7], tumor extension at rectal exploration, and core biopsy sampling.

Molecular markers are commonly used in the oncological setting to stage and evaluate the progression of diseases. To date, the only clinically implemented molecular marker in genito-urinary oncology is PSA, an organ- but not cancerspecific biomarker. One of the most common biomarkers in the oncological setting is $\mathrm{Ki}-67$, a marker of cell proliferation present in all phases of the cell cycle (G1, G2, S, M) except that in resting cells (G0). A systematic review demonstrated that $\mathrm{Ki}-67$ is an independent predictor of PCa outcomes in a large number of studies [8] especially if PSA, Gleason Score (GS), and tumor extent were also considered $[9,10]$.

According to the literature, another interesting prognostic biomarker with the potential to be implemented in clinical routine is Phosphatase and Tensin Homolog (PTEN) expression, which can be assessed by either immunohistochemistry (IHC) or fluorescent in situ hybridization (FISH) [11-13]. PTEN is a tumor suppressor whose deletion is associated with disease progression, rapid cancer dissemination, transition to castration-resistant $\mathrm{PCa}$, and poor outcomes [14].

Based on these premises, in the context of the prospective phase II study "Short-term high precision radiotherapy for early prostate cancer with concomitant boost to the dominant lesion, AIRC-IG-13218" [15, 16], we evaluated the correlation between tumor aggressiveness and clinical outcomes in PCa patients treated with ultra-hypofractionated radiotherapy (RT) as a proof of concept towards treatment personalization. The relevance of Ki-67 and PTEN in PCa staging was also assessed.

\section{Patients and methods}

Patient cohort. This study was conducted in the context of phase II clinical study "Short-term radiotherapy for early prostate cancer with concomitant boost to the dominant lesion" (AIRC IG-13218), ClinicalTrials.gov identifier: NCT01913717. The inclusion and exclusion criteria along with RT treatment characteristics and study design have already been described [15] and preliminary results have already been reported [16].

Briefly, between October 2014 and January 2018, patients with low- and intermediate-risk PCa were prospectively enrolled in the study and treated with ultra-hypofractionated RT at the Division of Radiation Oncology in the European Institute of Oncology IRCCS (IEO), Milan, Italy. This trial had been approved by the Ethics Committee of the IEO and Centro Cardiologico Monzino of Milan IEO; notification number S768/113. All procedures performed involving human participants were in accordance with the ethical standards of the institutional and/or national research committee and with the 1964 Helsinki Declaration and its later amendments or comparable ethical standards. In this research, no animals were involved. All patients signed written informed consent for radiation therapy and written informed consent for the use of the anonymized data for research or educational purpose.

Of the 65 patients included in the main trial, 19 underwent a second core biopsy of the highest PI-RADS DIL with in-bore magnetic resonance imaging targeted biopsy (MRI-TBx). Only in these second core biopsies, GS, Ki-67 status by an IHC test, and PTEN status by the FISH test were evaluated. The correlation between Ki-67 and PTEN and clinical outcomes were evaluated at the end of RT and after a median follow-up period of 2 years.

mp-MRI guided core biopsy assessment. Following the diagnostic TRUS-guided core biopsy and after having signed the dedicated informed consent, part of the patients underwent a second in-bore MRI-TBx on the highest PI-RADS lesion.

mp-MRI was performed using a 1.5-T MR scanner (Avanto, Siemens Medical Solutions, Erlangen, Germany) with a phased-array coil. mp-MRI protocol involved sagittal, coronal, and axial T2-weighted images, axial diffusion weighted, and a dynamic series of axial T1-weighted images obtained before, during, and after an injection of contrast agent.

As recommended by the European Society of Urogenital Radiology (ESUR) prostate MRI guidelines [17, 18], a PI-RADS category was assigned for each lesion, to express the likelihood of the presence of significant PCa through a 5 -point scale ( $1=$ very low probability of a clinically relevant tumor and $5=$ very high probability of a clinically relevant tumor). For each patient with more than 1 lesion, the highest PI-RADS category was considered. Based on this scale, only lesions with PI-RADS category $\geq 3$ were considered significant and included in the analysis.

The MRI parameters include also the EPE score and the ADC. Criteria for EPE are the following: abutment; irregularity and neurovascular bundle thickening; bulge, loss of capsule and capsular enhancement; measurable extracapsular disease; obliteration of the recto-prostatic angle. Diffusion weighted imaging (DWI) allows to calculate the apparent diffusion coefficient (ADC), a proportional qualitative and quantitative assessment of PCa aggressiveness.

PTEN and Ki-67 assessment. PTEN FISH was performed using a dual-color FISH probe set consisting of two Spectrum Green-labeled probe and a Spectrum Red-labeled commercial centromere 10 probe (IQFISH Break Apart Probe Agilent Technologies, Santa Clara, CA, USA) as a reference. The predominant red and green signal numbers were recorded for each FISH probe to assess an eventual PTEN deletion.

Homozygous deletion of PTEN was defined as a complete absence of PTEN FISH probe signals in $\geq 60 \%$ of tumor nuclei of the tissue spot, with the presence of one or two PTEN FISH signals in adjacent normal cells (Figure 1). Figures 2A and $2 \mathrm{~B}$ represent how PTEN deletion influences carcinogenesis in prostate cells. 
The Ki-67 assessment was performed through immunoassaying using a MIB-1 antibody (Dako). Cells were counted by an expert pathologist on hotspots of the core with the highest GG and/or the one with the most extensive neoplasm. The mean percentage of positive cells was estimated with a continuous variable.

Radiation therapy treatment planning and delivery. Computed tomography (CT) simulation, volume of interest contouring, and treatment delivery were performed following the previously described methodology [15].

The fractionation schedule consisted of a dose of $36.25 \mathrm{~Gy}$ in 5 fractions $(7.25 \mathrm{~Gy} /$ fraction) on the whole prostate (corresponding to $90.6 \mathrm{~Gy}$ in 45 fractions according to the linear quadratic model, assuming $\alpha / \beta=1.5 \mathrm{~Gy}$ for PCa) [19]. The DIL received a SIB of $37.5 \mathrm{~Gy}$ in 5 fractions ( $7.5 \mathrm{~Gy} /$ fraction), equivalent to $96.4 \mathrm{~Gy}$ with conventional fractionation. The treatment was delivered every other day.

Oncological outcomes. Oncological outcomes were evaluated in terms of biochemical and clinical failure and overall survival (OS). The biochemical response was assessed through trimestral PSA evaluation, while OS was defined as the time interval between the date of RT beginning and death from any cause. For patients lost to follow-up, information on vital status was obtained through municipal vital statistics offices. Time to biochemical failure was defined according to the Phoenix criterion (nadir PSA+2 ng/ml).

The diagnosis of clinical recurrence was based on the biochemical failure confirmed by imaging studies, i.e. [11C]-choline positron emission tomography with co-registered CT (PET/CT), whole-body MRI (WB-MRI), or whole-body CT scan. Core biopsy was not mandatory if all diagnostic elements were univocal (PSA evolution stating for biochemical recurrence, [11C]-choline-PET/CT or MRI findings).

\section{Results}

Study population. By the end of recruitment, 19 patients performed in-bore MRI-TBx highest PI-RADS DIL core biopsy without complications.

All patients had clinical stage cT1c-cT2c cN0 cM0 according to TNM 8th edition and a PSA $<10 \mathrm{ng} / \mathrm{ml}$, except 3 patients who had PSA $>10 \mathrm{ng} / \mathrm{ml}$.

The number of DIL(s) ranged from 1 to 3 . In particular, 6 patients (31\%) had 1 DIL, $10(53 \%)$ had 2 DIL, and $3(16 \%)$ had 3 DIL. Median prostate volume was $37.5 \mathrm{~cm}^{3}$ (IQR 30.45-44.33). Baseline characteristics per patient are reported in Table 1.

Oncological outcomes. As far as the re-evaluation of GS is concerned, for 11 patients the in-bore MRI-TBx confirmed the findings of the first random core biopsy. On the contrary, GS was upgraded for 5 patients, with 4 patients re-classified as intermediate-risk instead of low-risk, and one patient as high-risk instead of intermediate-risk. On the other hand, for 3 patients there was a downgrading, with two of them passing from intermediate-risk to low-risk and one from intermediate unfavorable risk to intermediate favorable risk. No patients with a low/intermediate Ki-67 value $(<15 \%$ sec. ISUP Consensus 6) had PTEN deletions, whereas 5 of 15 patients with high $\mathrm{Ki}-67$ had the deletion. A complete biological panel is summarized in Table 1 .

Follow-up at two years was available for the whole cohort, and 18 patients were found to be alive without evidence of disease (NED). One patient had a clinical local relapse and received a partial prostate re-irradiation (35 Gy in $5 \mathrm{fr}$ ) in
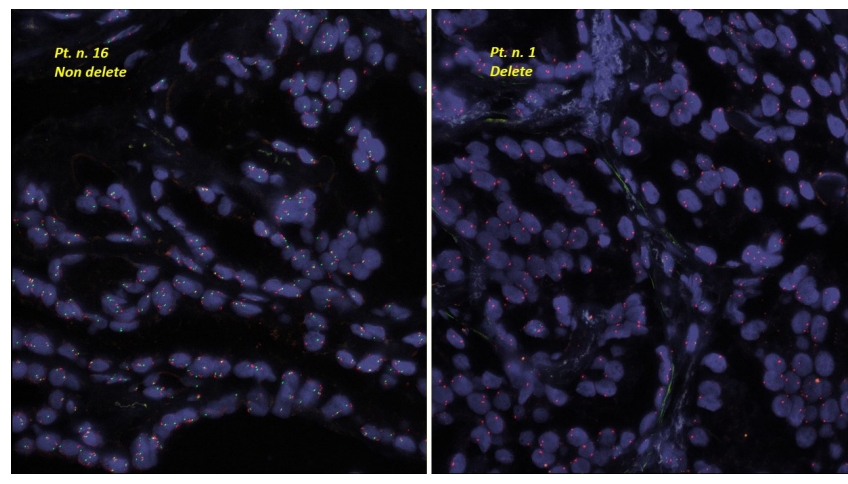

Figure 1. PTEN deletion assessment assay.

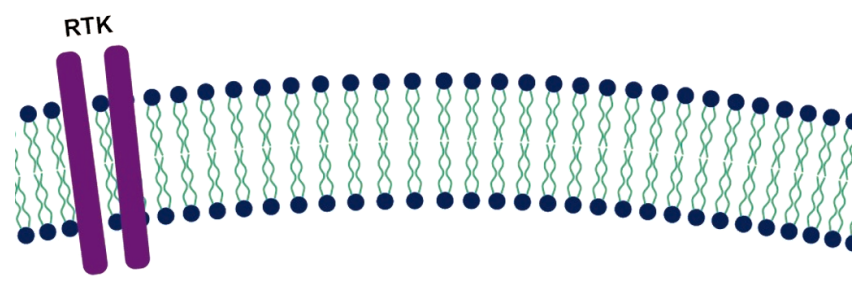

PTEN WT Cell

A

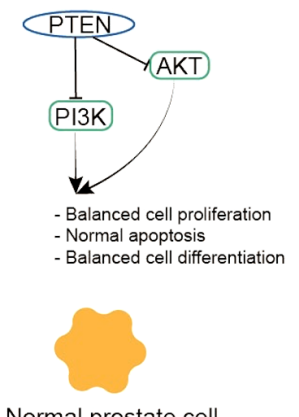

Normal prostate cell

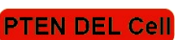

B

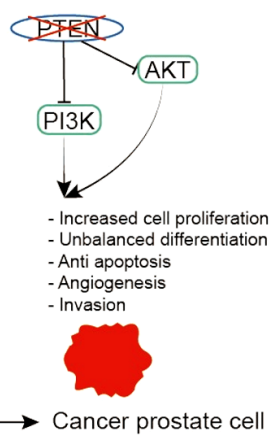

Figure 2. Receptor tyrosine kinases (RTKs) are major upstream regulators of the PI3K/AKT signaling. In particular, the PI3K pathway promotes cellular growth, invasion, and survival. PTEN is a prime antagonist of PI3K and therefore is a major negative regulator of the PI3-kinase pathway and of the serine-threonine kinase AKT. Activated AKT may phosphorylate a range of substrates, resulting in uncontrolled cellular growth and proliferation. PTEN with its lipid phosphatase activity is critical as a tumor suppressor (A) and, as seen in the image, PTEN deletion could result in apoptosis deregulation and cancer development (B). 
2018, NED was confirmed at the last follow-up. Of note, this relapse occurred in the only case of upgrading (from intermediate to high risk) described above.

No correlations between up/down-grading, PTEN deletion, Ki-67 expression, and mp-MRI characteristics (ECE, PI-RADS, ADC) were observed in the analyzed cohort.

\section{Discussion}

It is increasingly evident that common criteria for staging PCa are not sufficient to provide a comprehensive risk stratification of patients $[20,21]$. To improve treatments quality in $\mathrm{PCa}$, the integration of several radiological, biological, and clinical candidate biomarkers may be beneficial. In the era of personalized medicine, a more refined disease characterization would inform the clinical management, and guide personalized treatment intensification or de-escalation strategies, improving the overall therapeutic ratio in this clinical scenario.

In the present study, we performed an MRI-guided target core-biopsy in order to validate the proposed staging and we observed $42 \%$ of misclassification, with a $26 \%$ upgrading rate. In addition, we analyzed PTEN deletion and continuous Ki-67 expression in order to identify if either one of these parameters could be related to a worse prognosis. Unfortunately, our small sample size and the limited number of events did not allow us to perform a powered statistical analysis and to draw any conclusion.
The MRI-based PI-RADS category is a recognized independent diagnostic criterion of $\mathrm{PCa}[18,26]$ and it improves the assignment of patients to correct treatments. Moreover, the re-classification by targeted core biopsy is a promising practice to reduce misclassification and consequently underestimated therapies or overtreatments [22-24].

In fact, a recent publication by Kasivisvanathan et al. [25] confirmed that the test performance of MRI-guided target core biopsy in the detection of $\mathrm{PCa}$ is superior to that of systematic TRUS-guided core biopsy.

In addition, recent publications demonstrated that the majority of ISUP grade group 2 or higher PCa are corebiopsied proximally to mp-MRI-identified lesions [28-31], therefore suggesting a variable heterogeneity of neoplasia that contribute to eventually non-detection and misclassification.

Indeed, Pessoa et al. [22] reported a reclassification rate of $74.5 \%$ and $100 \%$ in PI-RADS category 4 and 5, respectively. According to Shaw et al. [32] that observed a $50 \%$ of upgraded PCa.

Another point to consider is the lack of validated biomarkers in PCa. The genomic risk assessments are highly prognostic, irrespective of cancer stage, risk group, or treatment type [33]. Despite the availability of histological material useful for further investigations beyond GS and ISUP grade, no integrative additional analyses are currently implemented in international guidelines and consequently in clinical practice. An example is represented by the well-

Table 1. Patients' tumor characteristics.

\begin{tabular}{|c|c|c|c|c|c|c|c|c|c|}
\hline $\begin{array}{l}\text { Patient } \\
\text { number }\end{array}$ & $\begin{array}{c}\text { iPSA } \\
(\mathrm{ng} / \mathrm{ml})\end{array}$ & $\begin{array}{c}\text { TRUS } \\
\text { Biopsy GS }\end{array}$ & $\begin{array}{l}\text { mp-MRI- } \\
\text { Biopsy GS }\end{array}$ & $\begin{array}{l}\text { up/down } \\
\text { grading }\end{array}$ & $\begin{array}{c}\text { Prostate } \\
\text { volume }\left(\mathrm{cm}^{3}\right)\end{array}$ & $\begin{array}{c}\text { PI-RADS } \\
\max \end{array}$ & ECE max & $\begin{array}{c}\text { Ki-67 expression } \\
(\%)\end{array}$ & $\begin{array}{c}\text { PTEN deletion } \\
\text { assessment }\end{array}$ \\
\hline 1 & 1.1 & $4+3$ & $3+4$ & down & $<50$ & 4 & 3 & 18 & deletion \\
\hline 2 & 8.1 & $4+3$ & $3+3$ & down & $<50$ & 4 & 3 & 18 & no deletion \\
\hline 3 & 5.95 & $3+4$ & $3+3$ & down & $>50$ & 3 & 3 & 16 & deletion \\
\hline 4 & 6.7 & $3+3$ & $3+3$ & confirmed & $<50$ & 5 & 4 & 6 & no deletion \\
\hline 5 & 4.08 & $3+4$ & $3+4$ & confirmed & $<50$ & 4 & 1 & 16 & no deletion \\
\hline 6 & 6.07 & $3+4$ & $3+4$ & confirmed & $<50$ & 3 & 3 & 40 & deletion \\
\hline 7 & 2.5 & $3+4$ & $3+4$ & confirmed & $>50$ & 3 & 2 & 10 & no deletion \\
\hline 8 & 12.5 & $3+4$ & $3+4$ & confirmed & $<50$ & 4 & 3 & 18 & no deletion \\
\hline 9 & 5.35 & $3+4$ & $3+4$ & confirmed & $<50$ & 4 & 3 & 18 & no deletion \\
\hline 10 & 7.41 & $3+3$ & $3+3$ & confirmed & $>50$ & 4 & 4 & 20 & no deletion \\
\hline 11 & 6.32 & $3+3$ & $3+3$ & confirmed & $<50$ & 3 & 1 & n.a. & no deletion \\
\hline 12 & 5.3 & $3+3$ & $3+3$ & confirmed & $<50$ & 4 & 2 & 16 & no deletion \\
\hline 13 & 4.5 & $3+4$ & $3+4$ & confirmed & $<50$ & 5 & 4 & 20 & deletion \\
\hline 14 & 5.66 & $3+4$ & $3+4$ & confirmed & $>50$ & 4 & 2 & 20 & no deletion \\
\hline 15 & 11.7 & $3+3$ & $4+3$ & up & $<50$ & 5 & 3 & 18 & no deletion \\
\hline 16 & 11.2 & $3+4$ & $4+4$ & up $^{*}$ & $<50$ & 5 & 1 & 35 & no deletion \\
\hline 17 & 7.98 & $3+3$ & $3+4$ & up & $<50$ & 4 & 2 & 14 & no deletion \\
\hline 18 & 7.7 & $3+3$ & $3+4$ & up & $<50$ & 3 & 3 & 15 & deletion \\
\hline 19 & 7.5 & $3+3$ & $3+4$ & up & $<50$ & 4 & 2 & 22 & no deletion \\
\hline
\end{tabular}

Note: ${ }^{*}$ patient who suffered a recurrence

Abbreviations: PSA-prostate-specific antigen; TRUS-transrectal ultrasounds; mp-MRI-multiparametric magnetic resonance imaging; PI-RADS-prostate imaging reporting and data system; ECE-extracapsular extension score; PTEN-phosphatase and tensin homolog 
known 22-gene Decipher test which appears to be superior to clinical-pathological models in several settings, including low- and intermediate-risk localized PCa, adjuvant therapy, biochemical relapse, and, most recently, in non-metastatic castration-resistant disease [33-36].

Among available histological biomarkers, Ki-67 is an old but still attractive one, due to its reproducibility, easy measurement technique, and low costs on a large-scale use [37]. Thanks to its peculiar characteristics, Ki-67 is largely used in clinical practice for many oncological diseases, particularly in breast, lung, pancreas, and brain tumors, and several studies demonstrated that its expression is directly correlated with worse prognosis (both cancer-specific and OS) [38-43]. Encouraged by these results, several studies explored the Ki-67 role in PCa [44, 45]. Bettencourt et al. [44] related $\mathrm{Ki}-67$ with an early progression and disease recurrence, while Pollack et al. [45] found a significant association between $\mathrm{Ki}-67$ and worse survival outcomes in patients treated with RT. Subsequently, Fisher et al. [10] identified a prognostic Ki-67 cut-off of $5 \%$ and $10 \%$, and Tretiakova et al. [46] found an association with ECE score. However, a comparison between these studies is made difficult by heterogeneous variables such as different endpoints and cut-offs defined.

Another common biomarker found principally in castration-resistant PCa is PTEN loss [47]. Despite promising results in the literature [49-52], because of an insufficient level of evidence, PTEN deletion cannot be yet considered an independent factor for PCa prognosis after treatments. However, a recent systematic review and metanalysis by Liu et al. [48] concluded that PTEN deletion could affect both the risk of PCa relapse after radical prostatectomy and the probability of biochemical relapse after RT.

Interestingly, a recent report from the ISUP Consultation Conference concluded that both $\mathrm{Ki}-67$ and PTEN are potentially useful prognostic biomarkers to be integrated with clinical parameters in grade 1 and 2 PCa ISUP groups, with the aim to help the clinician better select the patient's subgroup eligible for AS [53].

In line with our analysis, the above-mentioned consensus suggests that the implementation of in-bore MRI-guided target core biopsy, and PTEN and Ki-67 assessment, could represent a future strategy to improve personalized approaches, and the panelists underline the need for studies combining image-guided biopsies and molecular testing. The present exploratory study, even on a small cohort, and according to previous evidence, supports this consideration, demonstrating superiority of in-bore MRI-guided target core biopsy on DIL in patients' risk stratification if compared to a standard TRUS core biopsy.

The present study shows some relevant limitations. First of all, it is a subgroup analysis from the main trial mentioned above. Consequently, the low sample size underpowers the analysis and prevents further statistical considerations. Secondly, the median follow-up is too short to assess oncological outcomes in low-to-intermediate risk groups $\mathrm{PCa}$.

Further investigations need to be performed towards the identification of a pattern in the tumor aggressivenessresponse in $\mathrm{PCa}$ treated with ultra-hypofractionated RT. Nevertheless, our exploratory analyses could represent a hypothesis-generating study on this important issue.

Acknowledgments: This study was partially supported by Associazione Italiana per la Ricerca sul Cancro (AIRC), project IG13218 "Short-term High Precision Radiotherapy for Early Prostate Cancer With Concomitant Boost on the Dominant Lesion", registered at ClinicalTrials.gov (NCT01913717), by the Italian Ministry of Health with Ricerca Corrente and $5 \times 1000$ funds and by Accuray Inc. project entitled "Data collection and analysis of Tomotherapy and CyberKnife breast clinical studies, breast physics studies and prostate study". The Sponsors did not play any role in the study design, collection, analysis and interpretation of data, nor in the writing of the manuscript, nor in the decision to submit the manuscript for publication. Stefania Volpe was partially supported by the Italian Ministry of Health with Progetto di Eccellenza, which did not play any role in the study design, collection, analysis and interpretation of data, nor in the writing of the manuscript, nor in the decision to submit the manuscript for publication. Stefania Volpe MD, is a $\mathrm{PhD}$. student within the European School of Molecular Medicine (SEMM), Milan.

\section{References}

[1] DALL'ERA MA, ALBERTSEN PC, BANGMA C, CARROLL PR, CARTER HB et al. Active surveillance for prostate cancer: A systematic review of the literature. Eur Urol 2012; 62: 976-983. https://doi.org/10.1016/j.eururo.2012.05.072

[2] WIEGEL T, BARTKOWIAK D, BOTTKE D, BRONNER C, STEINER U et al. Adjuvant radiotherapy versus wait-andsee after radical prostatectomy: 10-year follow-up of the ARO 96-02/AUO AP 09/95 trial. Eur Urol 2014; 66: 243250. https://doi.org/10.1016/j.eururo.2014.03.011

[3] VAN DEN BERGH RCN, AHMED HU, BANGMA CH, COOPERBERG MR, VILLERS A et al. Novel tools to improve patient selection and monitoring on active surveillance for low-risk prostate cancer: A systematic review. Eur Urol 2014; 65: 1023-1031. https://doi.org/10.1016/j.eururo.2014.01.027

[4] LE JD, TAN N, SHKOLYAR E, LU DY, KWAN L et al. Multifocality and prostate cancer detection by multiparametric magnetic resonance imaging: Correlation with whole-mount histopathology. Eur Urol 2015; 67: 569-576. https://doi. org/10.1016/j.eururo.2014.08.079

[5] PUECH P, POTIRON E, LEMAITRE L, LEROY X, HABER GP et al. Dynamic Contrast-enhanced-magnetic Resonance Imaging Evaluation of Intraprostatic Prostate Cancer: Correlation with Radical Prostatectomy Specimens. Urology 2009; 74: 1094-1099. https://doi.org/10.1016/j.urology.2009.04.102 
[6] SCHAEFFER E, SRINIVAS S, ANTONARAKIS ES, ARMSTRONG AJ, BEKELMAN JE et al. NCCN Guidelines Insights: Prostate Cancer, Version 1.2021. J Natl Compr Canc Netw 2021; 19: 134-143. https://doi.org/10.6004/ jnccn.2021.0008

[7] VAN LEENDERS GJLH, VAN DER KWAST TH, GRIGNON DJ, EVANS AJ, KRISTIANSEN G et al. The 2019 International Society of Urological Pathology (ISUP) Consensus Conference on Grading of Prostatic Carcinoma. Am J Surg Pathol 2020; 44: e87-e99. https://doi.org/10.1097/ PAS.0000000000001497

[8] BERLIN A, CASTRO-MESTA JF, RODRIGUEZ-ROMO L, HERNANDEZ-BARAJAS D, GONZÁLEZ-GUERRERO JF et al. Prognostic role of Ki-67 score in localized prostate cancer: A systematic review and meta-analysis. Urol Oncol 2017; 35: 499-506. https://doi.org/10.1016/j.urolonc.2017.05.004

[9] BERNEY DM, GOPALAN A, KUDAHETTI S, FISHER G, AMBROISINE L et al. Ki-67 and outcome in clinically localised prostate cancer: Analysis of conservatively treated prostate cancer patients from the trans-atlantic prostate group study. Br J Cancer 2009; 100: 888-893. https://doi. org/10.1038/sj.bjc.6604951

[10] FISHER G, YANG ZH, KUDAHETTI S, MØLLER H, SCARDINO P et al. Prognostic value of Ki-67 for prostate cancer death in a conservatively managed cohort. Br J Cancer 2013; 108: 271-277. https://doi.org/10.1038/bjc.2012.598

[11] BISMAR TA, YOSHIMOTO M, VOLLMER RT, DUAN Q, FIRSZT $M$ et al. PTEN genomic deletion is an early event associated with ERG gene rearrangements in prostate cancer. BJU Int 2011; 107: 477-485. https://doi.org/10.1111/j.1464410X.2010.09470.x

[12] BISMAR TA, HEGAZY S, FENG Z, YU D, DONNELLY $B$ et al. Clinical utility of assessing PTEN and ERG protein expression in prostate cancer patients: a proposed method for risk stratification. J Cancer Res Clin Oncol 2018; 144: 2117-2125. https://doi.org/10.1007/s00432-018-2730-5

[13] SIRCAR K, YOSHIMOTO M, MONZON FA, KOUMAKPAYI IH, KATZ RL et al. PTEN genomic deletion is associated with p-Akt and AR signalling in poorer outcome, hormone refractory prostate cancer. J Pathol 2009; 218: 505-513. https://doi.org/10.1002/path.2559

[14] YOSHIMOTO M, CUNHA IW, COUDRY RA, FONSECA FP, TORRES CH et al. FISH analysis of 107 prostate cancers shows that PTEN genomic deletion is associated with poor clinical outcome. Br J Cancer 2007; 97: 678-685. https://doi. org/10.1038/sj.bjc.6603924

[15] TIMON G, CIARDO D, BAZANI A, GARIONI M, MAESTRI D et al. Rationale and protocol of AIRC IG-13218, short-term radiotherapy for early prostate cancer with concomitant boost to the dominant lesion. Tumori 2016; 102 : 536-540. https://doi.org/10.5301/tj.5000547

[16] TIMON G, CIARDO D, BAZANI A, MARVASO G, RIVA G et al. Short-term high precision radiotherapy for early prostate cancer with concomitant boost to the dominant lesion: Ad interim analysis and preliminary results of Phase II trial AIRC-IG-13218. Br J Radiol 2018; 91: 20160725. https://doi. org/10.1259/bjr.20160725
[17] BARENTSZ JO, RICHENBERG J, CLEMENTS R, CHOYKE P, VERMA $S$ et al. ESUR prostate MR guidelines 2012. Eur Radiol 2012; 22: 746-757. https://doi.org/10.1007/ s00330-011-2377-y

[18] WEINREB JC, BARENTSZ JO, CHOYKE PL, CORNUD F, HAIDER MA et al. PI-RADS Prostate Imaging - Reporting and Data System: 2015, Version 2. Eur Urol 2016; 69: 16-40. https://doi.org/10.1016/j.eururo.2015.08.052

[19] VAN LEEUWEN CM, OEI AL, CREZEE J, BEL A, FRANKEN NAP et al. The alfa and beta of tumours: A review of parameters of the linear-quadratic model, derived from clinical radiotherapy studies. Radiat Oncol 2018; 13: 96. https://doi. org/10.1186/s13014-018-1040-Z

[20] BOKHORST LP, VALDAGNI R, RANNIKKO A, KAKEHI Y, PICKLES T et al. A Decade of Active Surveillance in the PRIAS Study: An Update and Evaluation of the Criteria Used to Recommend a Switch to Active Treatment. Eur Urol 2016; 70: 954-960. https://doi.org/10.1016/j.eururo.2016.06.007

[21] KLOTZ L, VESPRINI D, SETHUKAVALAN P, JETHAVA V, ZHANG L et al. Long-term follow-up of a large active surveillance cohort of patients with prostate cancer. J Clin Oncol 2015; 33: 272-277. https://doi.org/10.1200/ JCO.2014.55.1192

[22] PESSOA RR, VIANA PC, MATTEDI RL, GUGLIELMETTI $\mathrm{GB}, \mathrm{CORDEIRO} \mathrm{MD}$ et al. Value of 3-Tesla multiparametric magnetic resonance imaging and targeted biopsy for improved risk stratification in patients considered for active surveillance. BJU Int 2017; 119: 535-542. https://doi. org/10.1111/bju.13624

[23] HU JC, CHANG E, NATARAJAN S, MARGOLIS DJ, MACAIRAN $\mathrm{M}$ et al. Targeted prostate biopsy in select men for active surveillance - Do the epstein criteria still apply? J Urol 2014; 192: 385-390. https://doi.org/10.1016/j. juro.2014.02.005

[24] OUZZANE A, RENARD-PENNA R, MARLIERE F, MOZER P, OLIVIER J et al. Magnetic Resonance Imaging Targeted Biopsy Improves Selection of Patients Considered for Active Surveillance for Clinically Low Risk Prostate Cancer Based on Systematic Biopsies. J Urol 2015; 194: 350-356. https://doi.org/10.1016/j.juro.2015.02.2938

[25] KASIVISVANATHAN V, RANNIKKO AS, BORGHI M, PANEBIANCO V, MYNDERSE LA et al. MRI-Targeted or Standard Biopsy for Prostate-Cancer Diagnosis. N Engl J Med 2018; 378: 1767-1777. https://doi.org/10.1056/NEJMoa1801993

[26] TURKBEY B, ROSENKRANTZ AB, HAIDER MA, PADHANI AR, VILLEIRS G et al. Prostate Imaging Reporting and Data System Version 2.1: 2019 Update of Prostate Imaging Reporting and Data System Version 2. Eur Urol 2019; 76: 340-351. https://doi.org/10.1016/j.eururo.2019.02.033

[27] PORPIGLIA F, CANTIELLO F, DE LUCA S, MANFREDI M, VELTRI A et al. In-parallel comparative evaluation between multiparametric magnetic resonance imaging, prostate cancer antigen 3 and the prostate health index in predicting pathologically confirmed significant prostate cancer in men eligible for active surveillance. BJU Int 2016; 118: 527-534. https://doi.org/10.1111/bju.13318 
[28] VAN DER LEEST M, CORNEL E, ISRAËL B, HENDRIKS R, PADHANI AR et al. Head-to-head Comparison of Transrectal Ultrasound-guided Prostate Biopsy Versus Multiparametric Prostate Resonance Imaging with Subsequent Magnetic Resonance-guided Biopsy in Biopsy-naïve Men with Elevated Prostate-specific Antigen: A Large Prospective Multicenter Clinical Study (Figure presented.). Eur Urol 2019; 75: 570-578. https://doi.org/10.1016/j.eururo.2018.11.023

[29] ROUVIÈRE O, PUECH P, RENARD-PENNA R, CLAUDON M, ROY C et al. Use of prostate systematic and targeted biopsy on the basis of multiparametric MRI in biopsy-naive patients (MRI-FIRST): a prospective, multicentre, paired diagnostic study. Lancet Oncol 2019; 20: 100-109. https://doi.org/10.1016/S1470-2045(18)30569-2

[30] BRYK DJ, LLUKANI E, TANEJA SS, ROSENKRANTZ AB, HUANG WC et al. The Role of Ipsilateral and Contralateral Transrectal Ultrasound-guided Systematic Prostate Biopsy in Men With Unilateral Magnetic Resonance Imaging Lesion Undergoing Magnetic Resonance Imaging-ultrasound Fusion-targeted Prostate Biopsy. Urology 2017; 102: 178-182. https://doi.org/10.1016/j.urology.2016.11.017

[31] MUTHIGI A, GEORGE AK, SIDANA A, KONGNYUY M, SIMON R et al. Missing the Mark: Prostate Cancer Upgrading by Systematic Biopsy over Magnetic Resonance Imaging/Transrectal Ultrasound Fusion Biopsy. J Urol 2017; 197: 327-334. https://doi.org/10.1016/j.juro.2016.08.097

[32] SHAW GL, THOMAS BC, DAWSON SN, SRIVASTAVA G, VOWLER SL et al. Identification of pathologically insignificant prostate cancer is not accurate in unscreened men. Br J Cancer 2014; 110: 2405-2411. https://doi.org/10.1038/ bjc. 2014.192

[33] SPRATT DE, YOUSEFI K, DEHESHI S, ROSS AE, DEN $\mathrm{RB}$ et al. Individual patient-level meta-Analysis of the performance of the decipher genomic classifier in high-risk men after prostatectomy to predict development of metastatic disease. J Clin Oncol 2017; 35: 1991-1998. https://doi. org/10.1200/JCO.2016.70.2811

[34] BERLIN A, MURGIC J, HOSNI A, PINTILIE M, SALCEDO A et al. Genomic Classifier for Guiding Treatment of Intermediate-Risk Prostate Cancers to Dose-Escalated Image Guided Radiation Therapy Without Hormone Therapy. Int J Radiat Oncol Biol Phys 2019; 103: 84-91. https://doi. org/10.1016/j.ijrobp.2018.08.030

[35] FENG FY, THOMAS S, SAAD F, GORMLEY M, YU MK et al. Association of Molecular Subtypes with Differential Outcome to Apalutamide Treatment in Nonmetastatic Castration-Resistant Prostate Cancer. JAMA Oncol 2021; 7: 1005-1014. https://doi.org/10.1001/jamaoncol.2021.1463.

[36] COOPERBERG MR, ERHO N, CHAN JM, FENG FY, FISHBANE $\mathrm{N}$ et al. The Diverse Genomic Landscape of Clinically Low-risk Prostate Cancer. Eur Urol 2018; 74: 444452. https://doi.org/10.1016/j.eururo.2018.05.014

[37] HOOGLAND AM, KWELDAM CF, LEENDERS GJLHV. Prognostic Histopathological and Molecular Markers on Prostate Cancer Needle-Biopsies: A Review. Biomed Res Int 2014; 2014: 341324. https://doi.org/10.1155/2014/341324
[38] NISHIMUKAI A, YAGI T, YANAI A, MIYAGAWA Y, ENOMOTO Y et al. High Ki-67 expression and low progesterone receptor expression could independently lead to a worse prognosis for postmenopausal patients with estrogen receptor-positive and HER2-negative breast cancer. Clin Breast Cancer 2015; 15: 204-211. https://doi.org/10.1016/j. clbc.2014.12.007

[39] INWALD EC, KLINKHAMMER-SCHALKE M, HOFSTÄDTER F, ZEMAN F, KOLLER M et al. Ki-67 is a prognostic parameter in breast cancer patients: Results of a large population-based cohort of a cancer registry. Breast Cancer Res Treat 2013; 139: 539-552. https://doi.org/10.1007/ s10549-013-2560-8

[40] WARTH A, CORTIS J, SOLTERMANN A, MEISTER M, BUDCZIES $J$ et al. Tumour cell proliferation (Ki-67) in non-small cell lung cancer: a critical reappraisal of its prognostic role. Br J Cancer 2014; 111: 1222-1229. https://doi. org/10.1038/bjc.2014.402

[41] HAMILTON NA, LIU TC, CAVATIAO A, MAWAD K, CHEN L et al. Ki-67 predicts disease recurrence and poor prognosis in pancreatic neuroendocrine neoplasms. Surgery 2012; 152: 107-113. https://doi.org/10.1016/j. surg.2012.02.011.

[42] ZENG A, HU Q, LIU Y, WANG Z, CUI X et al. IDH1/2 mutation status combined with Ki-67 labeling index defines distinct prognostic groups in glioma. Oncotarget 2015; 6: 30232-30238. https://doi.org/10.18632/oncotarget.4920

[43] SARICANBAZ I, KARAHACIOGLU E, EKINCI O, BORA H, KILIC D et al. Prognostic significance of expression of CD133 and ki-67 in gastric cancer. Asian Pac J Cancer Prev 2014; 15: 8215-8219. https://doi.org/10.7314/ apjcp.2014.15.19.8215

[44] BETTENCOURT MC, BAUER JJ, SESTERHENN IA, MOSTOFI FK, MCLEOD DG et al. Ki-67 expression is a prognostic marker of prostate cancer recurrence after radical prostatectomy. J Urol 1996; 156: 1064-1068.

[45] POLLACK A, DESILVIO M, KHOR LY, LI R, AL-SALEEM TI et al. Ki-67 staining is a strong predictor of distant metastasis and mortality for men with prostate cancer treated with radiotherapy plus androgen deprivation: Radiation Therapy Oncology Group trial 92-02. J Clin Oncol 2004; 22: $2133-$ 2140. https://doi.org/10.1200/JCO.2004.09.150

[46] TRETIAKOVA MS, WEI W, BOYER HD, NEWCOMB LF, HAWLEY S et al. Prognostic value of Ki67 in localized prostate carcinoma: A multi-institutional study of $>1000$ prostatectomies. Prostate Cancer Prostatic Dis 2016; 19: 264-270. https://doi.org/10.1038/pcan.2016.12

[47] JAMASPISHVILI T, BERMAN DM, ROSS AE, SCHER HI, DE MARZO AM et al. Clinical implications of PTEN loss in prostate cancer. Nat Rev Urol 2018; 15: 222-234. https://doi. org/10.1038/nrurol.2018.9

[48] LIU R, ZHOU J, XIA S, LI T. The impact of PTEN deletion and ERG rearrangement on recurrence after treatment for prostate cancer: a systematic review and meta-analysis. Clin Transl Oncol 2020; 22: 694-702. https://doi.org/10.1007/ s12094-019-02170-3 
[49] LEAPMAN MS, NGUYEN HG, COWAN JE, XUE L, STOHR B et al. Comparing Prognostic Utility of a Singlemarker Immunohistochemistry Approach with Commercial Gene Expression Profiling Following Radical Prostatectomy. Eur Urol 2018; 74: 668-675. https://doi.org/10.1016/j.eururo.2018.08.020

[50] MITHAL P, ALLOTT E, GERBER L, REID J, WELBOURN $\mathrm{W}$ et al. PTEN loss in biopsy tissue predicts poor clinical outcomes in prostate cancer. Int J Urol 2014; 21: 1209-1214. https://doi.org/10.1111/iju.12571

[51] BRAMHECHA YM, ROUZBEH S, GUÉRARD KP, SCARLATA E, BRIMO F et al. The combination of PTEN deletion and 16p13.3 gain in prostate cancer provides additional prognostic information in patients treated with radical prostatectomy. Mod Pathol 2019; 32: 128-138. https://doi. org/10.1038/s41379-018-0107-6
[52] JAMASPISHVILI T, PATEL PG, NIU Y, VIDOTTO T, CAVEN I et al. Risk Stratification of Prostate Cancer through Quantitative Assessment of PTEN Loss (qPTEN). J Natl Cancer Inst 2020; 112: 1098-1104. https://doi.org/10.1093/ jnci/djaa032

[53] LOTAN TL, TOMLINS SA, BISMAR TA, VAN DER KWAST TH, GRIGNON D et al. Report From the International Society of Urological Pathology (ISUP) Consultation Conference on Molecular Pathology of Urogenital Cancers. I. Molecular Biomarkers in Prostate Cancer. Am J Surg Pathol 2020; 44: e15-e29. https://doi.org/10.1097/PAS.0000000000001450 